\title{
Remediation of Diesel Contaminated Soils Using Surfactants: Coulumn Study
}

\author{
${ }^{1}$ Salehian, E., ${ }^{2}$ A. Khodadadi and ${ }^{3}$ B. Hosseini \\ ${ }^{1,2}$ Department of Civil and Environmental Engineering, \\ Faculty of Engineering, Tarbiat Modares University, Tehran, Iran \\ ${ }^{3}$ Department of Civil and Environmental Engineering, \\ Texas Tech University, College of Engineering, USA
}

Received 2012-02-04; Revised 2012-02-27; Accepted 2012-06-18

\begin{abstract}
This study presents the experimental remediation studies of diesel contaminated soil with Sodium Deducible Sulfate (SDS) as surfactants using column tests. Sandy selected soil had the grain size distribution of \# 40 meshes to the \# 200 mesh range. The soil columns were contaminated with adequate diesel amount to achieve the concentration of 10000 and $20000 \mathrm{ppm}$ in soil. $0.1,0.2,0.3,0.4$ percent of surfactants and $\mathrm{pH}$ values of 4, 7, 9 and 11, were examined. After $72 \mathrm{~h}$, washing began and all tests were continued up to 10 pore volume and the trend of remediation and permeability of soil during the test was investigated. $\mathrm{pH}$ and TPH of outlet solution measured during 2, 4, 6 and 10 pore volumes. Times were recorded during 0.67, 1, 1.33, 2, 3.33, 4, 5.67, 6, $7.33,8,8.67,9.33$ and 10 pore volumes, in order to calculate permeability values. Results showed that in all states the quantity of remediation for acidic states was very low and efficiency of remediation when using only water was about (1:3) of maximum amount. For soil with initial contaminant concentration of $10000 \mathrm{ppm}$ the maximum efficiency is for surfactant in the concentration of 0.3 and $\mathrm{pH}=11$ and for soil with initial contamination amount of $20000 \mathrm{ppm}$ the maximum efficiency is for surfactant in the concentration of 0.1 and $\mathrm{pH}=11$. By increasing the amount of surfactant concentration, the permeability of soil decreased and in $\mathrm{pH}=$ 11 the amount of permeability is maximum. With increasing initial contamination quantity rate of increasing of remediation and permeability decreased. Consequently in the low level of contamination the effect of washing solution $\mathrm{pH}$ value in soil remediation and permeability is more in comparing with high level of contamination. For initial contamination of $10000 \mathrm{ppm}$ optimum removal efficiency obtained $35 \%$ for surfactant of $0.3 \%$ and $\mathrm{pH}=11$. For initial contamination of $20000 \mathrm{ppm}$, optimum removal efficiency is obtained as $45 \%$ for $0.1 \%$ of surfactant and $\mathrm{pH}=11$. Using of higher soil column, sampling from different elevation for investigating remediation trend in height and surveying temperature effect on diesel contaminated soil remediation can help to modification procedure and improvement of efficiency.
\end{abstract}

Keywords: Sodium Dedocyle Sulfate (SDS), Critical Micelle Concentration (CMC), maximum efficiency, surfactant amounts, permeability decreased

\section{INTRODUCTION}

Iran is subjected to oil pollution because of its oil resources, petrochemical productivity and transportations. Therefore finding a solution for soil remediation is one of high importance. Soil remediation methods are presented in three main parts; biological, physical and chemical and all other methods are related to these three main methods. Soil contamination by hydrophobic components is a main type of pollution. Up to now, various remediation techniques have been investigated. (Khalladi et al., 2009).
Between them, the washing processes with surfactants is themost used. The main items of these methods consists of the mobilization the solubilization of hydrocarbons by lowering the interfacial tension at the soil and water phase interfaces. Surfactant soil remediation is done by removing organic molecules adsorbed on soil and catched in the pores, continued by their encapsulation within micelles formed at a concentration greater than the Critical Micelle Concentration (CMC) (Khalladi et al., 2009).

Several methods of soil remediation have been experienced in laboratories which are not applicable for 
full-scale usages (Chang et al., 2010; Darban et al., 2011). There were many studies about ex-situ soil remediation. Contaminated soil were excavated from the site and transferred to another place to be washed. Washing materials and contaminated soil were mixed by water to be remediated. These methods need less time of operation but the cost is high and in some cases soil transportation through residential zones will cause some health and environmental problems. This study will provide an overview of a laboratory research for remediation of soil in a column and under gravity force. This method is more applicable and also the cost of the operation is less than other methods mentioned above. This method needs less time than biological methods and weather condition has low effect on this. Researches demonstrate, this method is proper for both ex-situ and in-situ remediation methods USEPA, 1998. Diesel fuel is amixture ofmore than 2000 compounds, which cannot be all separated by chromatography (Coulon et al., 2005; Feng et al., 2001). Soil washing was used for soil contaminated with heavy metals in addition to oil (Anderson, 1995; Anderson et al., 1999).

Soil washing mechanism is the extracting of contaminants from water by dissolving them in solvents. In earlier studies, water was used to dissolve contaminants; however additives are used to enhance the washing efficiency today, which decreases the time of operation. Additives consist of washing compounds, organic and inorganic acids, Sodium Hydroxide and, which can remove soluble contaminants (Abdul et al., 1990). Washing methods for soils of high permeability gives more removal efficiency.

The extraction of hydrocarbons from a sandy soil by surfactants is governed by mass transfer between solid, liquid and micellare phases. Moreover, the hydrocarbon solubility is highly dependent on the flow rate of surfactant solution. (Taylor et al., 2001). Soil washing using surfactants was innovated for soils contaminated with oil hydrocarbons. Clay content of the soil is a significant factor in washing because interfacial tension of the surfactant and clay will decrease surfactant concentration. First, contaminated zone should be identified for in-situ washing since washing operation's efficiency is related to soil characteristics and precise information about soil is necessary; grain size distribution, physic-chemical properties and their variation through depth, moisture content, organic material content, cationic exchange capacity and permeability. Remediation of soils contaminated with oil products with less content of pollution and larger particle sizes, in same conditions, gives more removal efficiency than soils with higher pollution and smaller particle sizes (Urum et al., 2004). Soils contaminated with oil products had the efficiency of $90-98 \%$ in ex-situ remediation using enhanced washing compounds (Lee et al., 2004). There is not enough information about full scale projects of in-situ soil remediation, but the principles are that after obtaining above information, some wells are used to pass the surfactants and according to soil permeability, gravity force or pumping is used to pass the surfactant through the soil. Depends on projects' zone, materials produced during project is extracted by pumps or entered to the subsurface water then it is collected and treated. Another research held on sandy media which had the initial contamination of $1000 \mathrm{ppm}$. Medias up to pore volume of 20 were washed by anionic surfactant, JBR425 and contaminant removal was $67 \%$ for this content of surfactant (Mulligan and Eftekhari, 2003). PCE removal efficiency in a sandy soil, with $15 \mathrm{~cm}$ height, $5 \mathrm{~cm}$ diameter and with $750 \mathrm{~mL}$ of surfactant solvent, was 44, 42 and $75 \%$ for anionic, no anionic and mixture of surfactant, respectively (Lee et al., 2004). Using surfactant for soil washing has been performed for several years, but because of problems such as soil blockage, reduction of permeability and hydraulic conductivity more investigations are needed yet. These problems are due to reactions between surfactants, organic materials and clay and congealing soil surface. Since permeability reduction causes in decreasing surfactant penetration, remediation time increases and removal efficiency decreases. Soil permeability is one of the most important parameters for soil washing which should be studied precisely due to site conditions and prior to performing any remediation. Surfactant efficiency in the remediation of contaminated soils is restricted by their adsorption on the soil. (Shen, 2000).

The soil remediation in a column of diesel contaminated soil with the natural penetration of surfactants using Sodium Dedocyle Sulfate (SDS) which would be more reliable to use in full-scale projects.

\section{MATERIALS AND METHODS}

Sodium Dedocyle Sulfate (SDS) was used as anionic surfactant which was manufactured by Merck Company in Germany. Critical Micelle Concentration (CMC) of this surfactant is 0.2 . Surfactant's characteristics are shown in Table 1. CMC is the most important parameter for each surfactant which describes surfactant's behaviour. CMC is the concentration in which the micelles begin to form. By increasing the surfactant's amount, monomers are transformed to micelles. In this point, surfactant meets the lowest surface tension. 


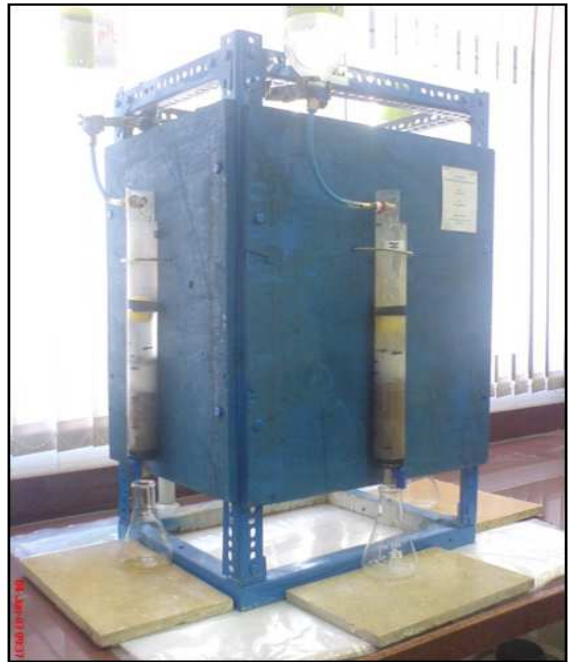

Fig. 1. Pilot plant's overall design

Table 1. Characteristics of SDS surfactant

\begin{tabular}{|c|c|}
\hline Characteristic & Description \\
\hline Surfactant type & Anionic \\
\hline Chemical formula & $\mathrm{C}^{12} \mathrm{H}^{25} \mathrm{NaO}^{4} \mathrm{~S}-\mathrm{C}^{12} \mathrm{H}^{25} \mathrm{OSO}^{2} \mathrm{ONa}$ \\
\hline CMC (\%) & $0.173-0.23$ \\
\hline Molecular weight & $288.38 \mathrm{~g} \mathrm{~mol}^{-1}$ \\
\hline Melting point & $204-207^{\circ} \mathrm{C}$ \\
\hline $\begin{array}{l}\text { Density } \\
\text { pH 6-9 }\left(10 \mathrm{~g} \mathrm{~L}^{-1} \text {, }\right. \\
\left.\mathrm{H}^{2} \mathrm{O}, 20^{\circ} \mathrm{C}\right)\end{array}$ & $20 \mathrm{~g} / \mathrm{cm}^{3}\left(1.1^{\circ} \mathrm{C}\right)$ \\
\hline Solubility in water & $150 \mathrm{~g} \mathrm{~L}^{-1}\left(20^{\circ} \mathrm{C}\right)$ \\
\hline Structure & \\
\hline
\end{tabular}

Table 2. Soil samples' characteristics

\begin{tabular}{ll}
\hline Characteristic & Description \\
\hline Soil type & Sandy \\
Void ratio (e) & 0.68 \\
Porosity (n) & 0.4 \\
Dry soil density, $\mathrm{g}_{\mathrm{d}}$ & $1.55\left(\mathrm{gr} / \mathrm{cm}^{3}\right)$ \\
$\mathrm{G}_{\mathrm{s}} 2.66$ & \\
$\mathrm{pH} 9$ & \\
Solubility in water & $150 \mathrm{gL}^{-1}\left(20^{\circ} \mathrm{C}\right)$ \\
Electrical conductivity & $158\left(\mathrm{~m}_{\mathrm{s}} / \mathrm{cm}\right)$ \\
\hline
\end{tabular}

Sandy soils were selected as testing samples and have the grain size distribution of \# 40 meshes to the \# 200 mesh range. Soils were washed with $0.1 \mathrm{~N}$ sulphuric acid, afterwards distilled water was injected for washing. The samples were dried out in an oven at $62^{\circ} \mathrm{C}$ for $24 \mathrm{~h}$. Soil characteristics are shown in Table 2.

Pilot plant consists of 3 plexi-glass columns with $50 \mathrm{~cm}$ height and $4 \mathrm{~cm}$ diameter. Surfactant mixture and water were located at the top of the pilot, in a one litre volume basin. And water is conducted to the column using a hose. Permeability measurements are performed in both constanthead and reducing-head conditions. In this study constanthead method was used. Pilot plant is shown in Fig. 1. Columns were adjusted on a vibration table with $1 \mathrm{~cm} / \mathrm{min}$ speed. They were filled by soil to the adequate height to achieve necessary compression and uniformity. After this step, columns were installed on a four leg steel structure, on considered positions. Fine coarse soil was used to fill on top of the columns with $1 \mathrm{~cm}$ height to prevent turbulences caused by water, surfactant and soil contact.

The soil columns were contaminated with adequate diesel amount to achieve the concentration of 10000 and $20000 \mathrm{ppm}$ in soil. After contamination, the columns were held for $72 \mathrm{~h}$ without any operation in order to resume reaction among diesel and soil particles, after $72 \mathrm{~h}$ washing began. As the goal of this study was to optimization of the $\mathrm{pH}$ and surfactant amount with permeability evaluation, 10 and $20 \mathrm{mg} \mathrm{g}^{-1}$ contaminant to soil portion for initial contamination, $0.1,0.2,0.3,0.4$ percent of surfactants and $\mathrm{pH}$ values of 4, 7, 9 and 11, were examined. In order to find out the surfactant's effect, all washing operations were performed using water (buffer solution) under several $\mathrm{pH}$ values and contamination amount. After $72 \mathrm{~h}$, washing began and solution basin was filled to be penetrated into the soil gradually. Washing was continued until reaching 10 pore volume and $\mathrm{pH}$ and TPH of outlet solution measured during 2, 4, 6 and 10 pore volumes. Times were recorded during $0.67,1,1.33,2,3.33,4,5.67,6,7.33,8,8.67,9.33$ and 10 pore volumes, in order to calculate permeability values and it's variations by depicting a more precise curve.

\section{RESULTS}

\subsection{Diesel Removal}

For the first run, removal efficiencies were investigated for initial contamination of $10000 \mathrm{ppm}$ and then for $20000 \mathrm{ppm}$.

Initial contamination of $10000 \mathrm{ppm}$ : Soil columns were contaminated with $10000 \mathrm{ppm}$ diesel, then washing was performed under different conditions. Figure 1 shows the removal efficiency under various $\mathrm{pH}$ values, surfactant and water amounts.

\subsection{Initial Contamination of 20000 ppm}

In the second part of the experiments, soil columns were contaminated with diesel of $20000 \mathrm{ppm}$ concentration and washing was performed under different conditions. Figure 4 shows the removal efficiency under various $\mathrm{pH}$ values, surfactant and water amounts. 


\subsection{Soil Permeability Evaluation}

Soil permeability was evaluated in initial contamination of both 10000 and $20000 \mathrm{ppm}$. Permeability varies during the test as a result of reactions among soil particles, surfactant and contaminant. To depict the charts, permeability was measured at pore volume of 10 .

\subsection{Initial Contamination of $10000 \mathrm{ppm}$}

At first, soil columns were tested for contamination of $10000 \mathrm{ppm}$. Outlet flow rates were recorded for several times during the test and permeability calculated in $\mathrm{cm} / \mathrm{sec}$. Figure 6 shows the permeability values for different conditions.

\subsection{Initial Contamination of 20000 ppm}

In the second part, soil columns were tested for 20000 ppm contamination and permeability was evaluated. Figure 8 shows the permeability values for different test conditions.

\section{DISCUSSION}

\subsection{Diesel Removal}

\subsection{Initial Contamination of 10000 ppm}

According to the Fig. 2, by increasing the surfactant amount, efficiency is increased and in 0.3 percent of surfactant, there was 35\% removal. Efficiency increasing progress have lower rate until 0.2 percent of surfactant, after that the rate is significantly decreased. As it is understood from Fig. 2, by adding the surfactant amount from 0.3-0.4 percent, efficiency is not only increased, but also decreased. Contaminated soil remediation is performed under progress which finally comes in to a balance in contamination, $\mathrm{pH}$ and surfactant amounts. The optimum point of the efficiency curve is like a parabola's extreme point that the less or more amounts of surfactant will result in a less efficiency. 0.3 percent of surfactant is the optimum point and with more amounts of surfactants, additional reactions between surfactant, contaminant and soil particles occurs that separation and removal of surfactant and diesel attached to soil is not applicable by water and results in a less efficiency. Figure 3 shows the removal efficiency variations with respect to increasing $\mathrm{pH}$ for different values of $\mathrm{pH}$, surfactant and also water amounts. As it demonstrated in Fig. 3, efficiency rises by increasing values of $\mathrm{pH}$.

This raise is higher for $\mathrm{pH}$ values from 4-7 and 9-11. As the figure shows, by increasing $\mathrm{pH}$ values from 7-9, no significant differences happened in remediation. In all cases, the efficiency is less in acidic phases in comparison with basic phases. The reason of higher efficiency in basic and neural phases would be the higher solubility of the oils.

\subsection{Initial Contamination of 20000 ppm}

According to Fig. 4, by increasing the surfactant amount, removal efficiency is decreased. In all cases the initial contamination is doubled, in comparison with the last case. In contamination concentration of $10000 \mathrm{ppm}$ removals efficiency loss, begins from the $0.3-0.4 \%$ of surfactant. In second run, by increasing the initial contamination, this amount decreased to $0.1-0.2 \%$ of surfactant. The other factor which decreases the removal efficiency since surfactant amount is increasing, is the reaction between additional amount of surfactant and soil particles which makes the separation and transporting of the diesel and surfactant difficult. By increasing the surfactant amount the number of reactions increases and gellike compounds produced at the surface of soil particles and rate of efficiency decreasing, increases. Figure 5 shows the diesel removal efficiency with respect to several $\mathrm{pH}$ values, surfactant and water amounts.

It is demonstrated from Fig. 5, the remediation efficiency variations are not significant with respect to $\mathrm{pH}$ value increase. It is concluded that in higher amounts of contamination due to test's conditions, surfactant amount is a more determinant factor in comparison with $\mathrm{pH}$ values. In fact, $\mathrm{pH}$ role is making the separation of diesel and soil easy and when the contamination is too high, prominent reaction is the reaction between surfactant and soil particles. Therefore in initial contamination of $20000 \mathrm{ppm}$, by increasing $\mathrm{pH}$ values, removal efficiency wouldn't very much.

\subsection{Soil Permeability Evaluation}

\subsection{Initial Contamination of $10000 \mathrm{ppm}$}

As it is shown in Fig. 6, by increasing the surfactant amount, permeability decreases. Permeability is the most for $\mathrm{pH}=11$, except in 0.4 percent of surfactant. Differences between the permeability in $\mathrm{pH}=11$ and other $\mathrm{pH}$ values, is the most at first (for 0.1 percent of surfactant amount).

By adding the surfactant amount, this difference decreases until in $0.4 \%$ of surfactant which is negative. This is caused by the balance factor which has been mentioned above. Increasing $\mathrm{pH}$ values along with surfactant amounts cause reaction among soil particles, surfactant and diesel which results in congealing soil surface and reduction of permeability. Figure 7 shows the soil permeability for different test conditions under 10000 ppm concentration of diesel. 
According to Fig. 7, soil permeability for water is the most rather than other surfactants in all $\mathrm{pH}$ values. For $\mathrm{pH}$ values of 4-9 for all surfactants, no significant difference occurred in permeability values, but for $\mathrm{pH}$ values of 9-11, it was noticeable.

\subsection{Initial Contamination of 20000 ppm}

In this case like previous one, by increasing surfactant amount, permeability decreases. The difference between the Fig. 6 and 8 is that permeability reduces intensively for $0.2 \%$ and more of surfactant, in Fig. 8. This is caused by reactions between additional surfactant amount and contamination. In fact, extra amount of diesel in soil results in this intense loss. Figure 9 shows different amounts of soil permeability for different test conditions.

In this case, $\mathrm{pH}$ value increasing have no significant impact on soil permeability and there is a negligible soil permeability difference between $\mathrm{pH}=11$ test and other tests. According to Fig. 7 and 9, for contamination of $10000 \mathrm{ppm}$, it is concluded that in high amount of contamination due to soil characteristics and test conditions, surfactant amount's impact on soil permeability is more significant than $\mathrm{pH}$ values.

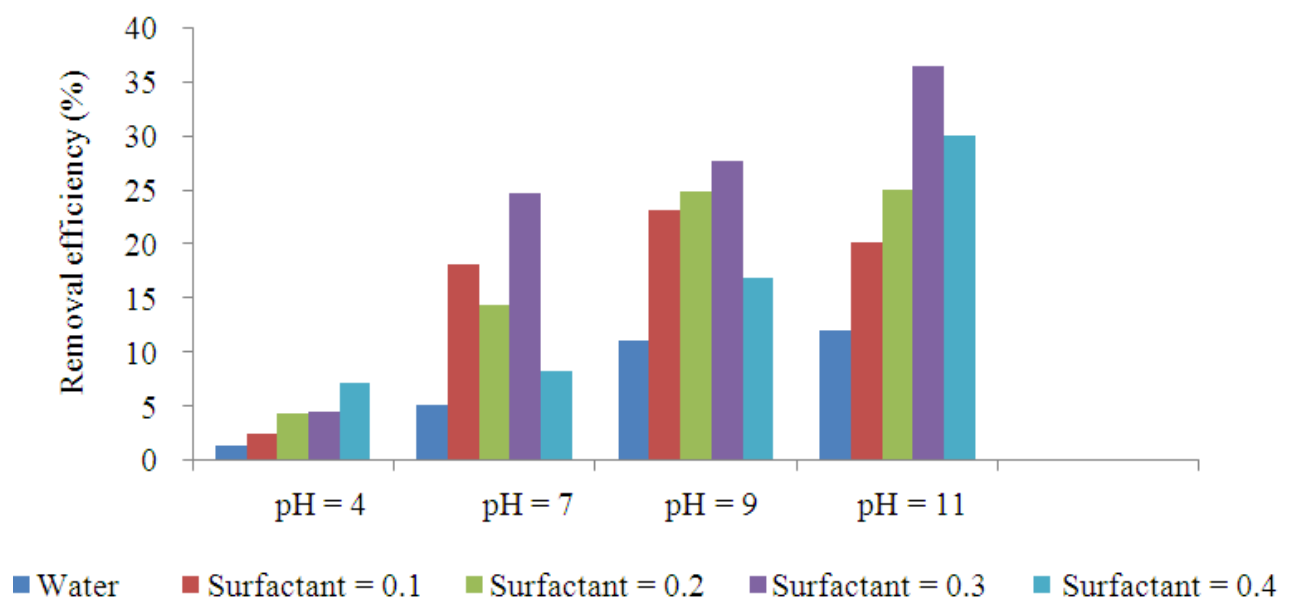

Fig. 2. Diesel removal efficiency (\%) with respect to increasing surfactant amount (Diesel concentration: 10000ppm)

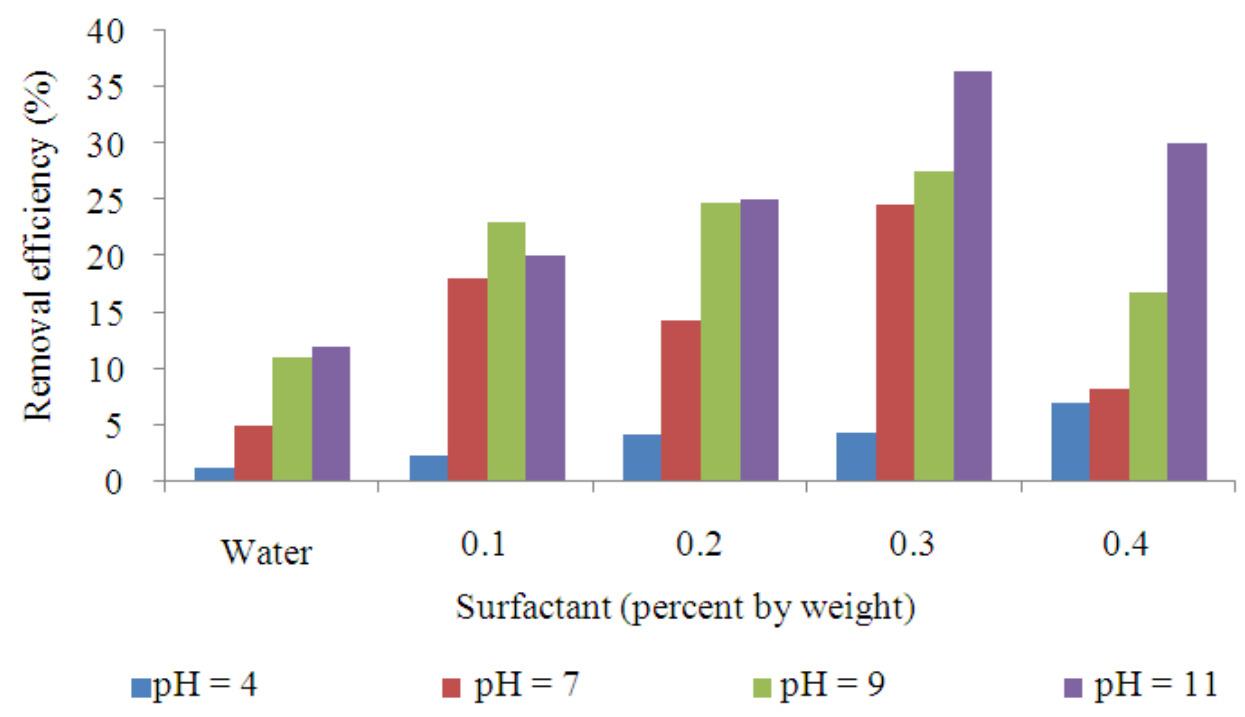

Fig. 3. Removal efficiencies (\%) with respect to increasing pH values (Diesel concentration: $10000 \mathrm{ppm}$ ) 
Salehian, E. et al. / American Journal of Environmental Science 8 (4) (2012) 352-359

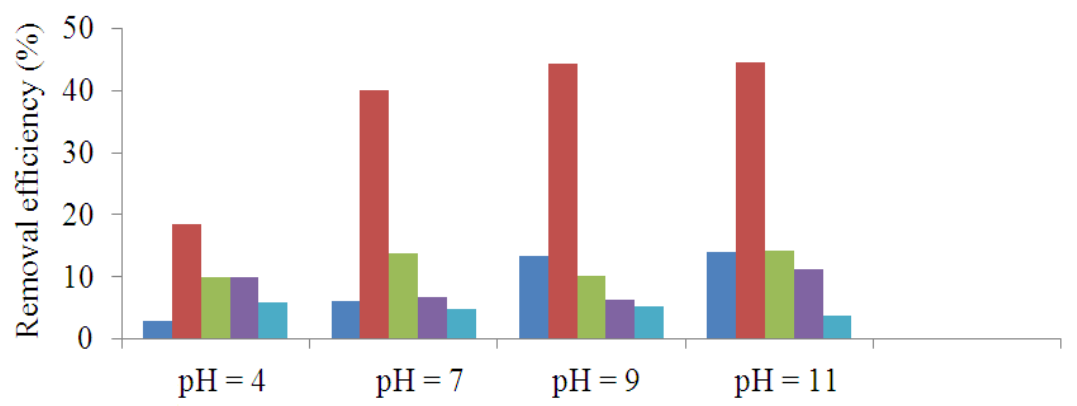

$\square$ Water $\quad$ Surfactant $=0.1 \quad \square$ Surfactant $=0.2 \quad \square$ Surfactant $=0.3 \quad \square$ Surfactant $=0.4$

Fig. 4. Removal efficiencies (\%) with respect to increasing surfactant amounts (Diesel concentration: $20000 \mathrm{ppm}$ )

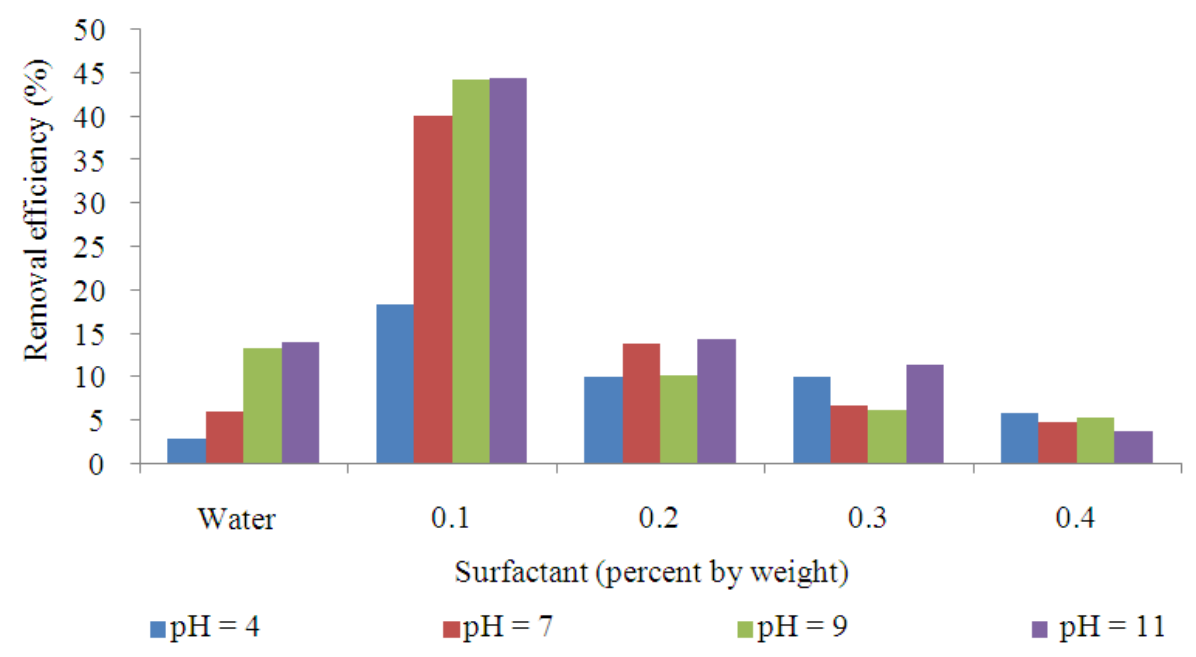

Fig. 5. Removal efficiencies (\%) with respect to increasing pH values (Diesel concentration: $20000 \mathrm{ppm}$ )

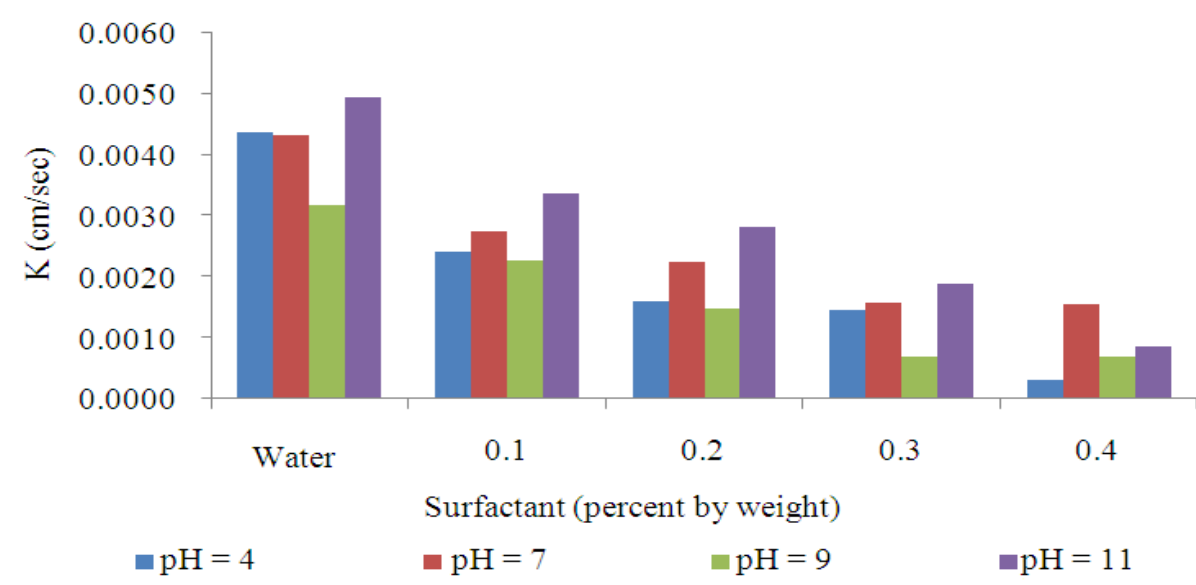

Fig. 6. Soil permeability for different conditions with respect to increasing surfactant amounts (Diesel concentration: $10000 \mathrm{ppm})$ 
Salehian, E. et al. / American Journal of Environmental Science 8 (4) (2012) 352-359

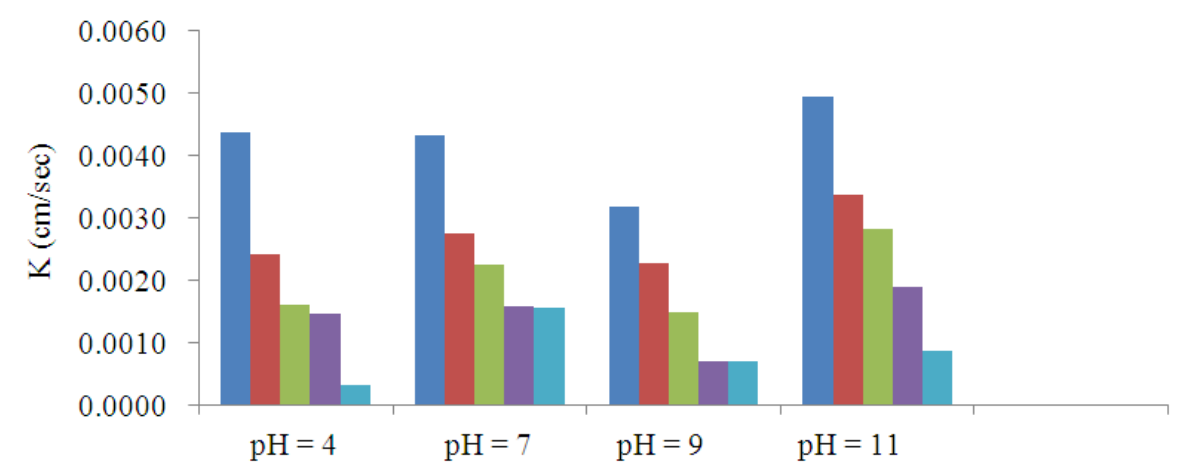

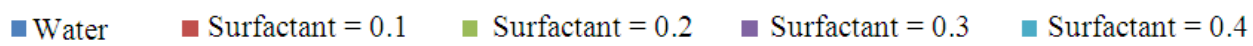

Fig. 7. Soil permeability for different conditions with respect to increasing $\mathrm{pH}$ values (Diesel concentration: $10000 \mathrm{ppm})$

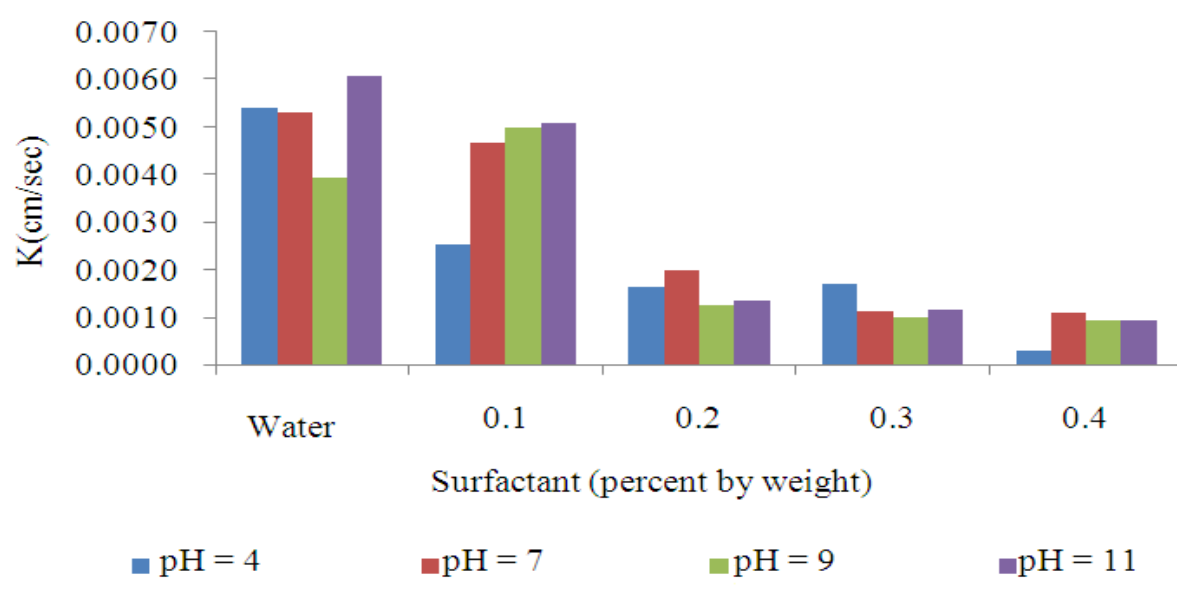

Fig. 8. Soil permeability for different conditions with respect to increasing surfactant amounts (Diesel concentration: 20000 ppm)

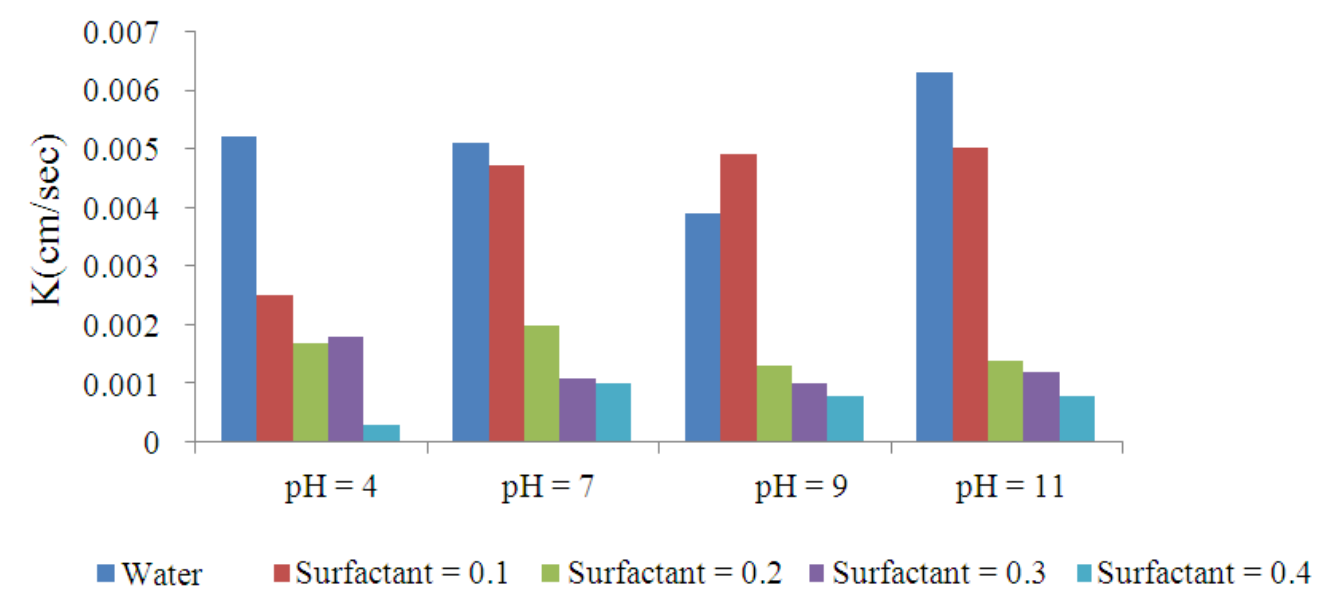

Fig. 9. Soil permeability for different conditions with respect to increasing pH values (Diesel concentration: $20000 \mathrm{ppm}$ ) 


\section{CONCLUSION}

Due to soil characteristics, researches should be held in each zone individually. In this study for initial contamination of $10000 \mathrm{ppm}$ and soil characteristics considered before, optimum removal efficiency obtained $35 \%$ for surfactant of $0.3 \%$ and $\mathrm{pH}=11$. For initial contamination of $20000 \mathrm{ppm}$ and soil characteristics mentioned above, optimum removal efficiency is obtained as $45 \%$ for $0.1 \%$ of surfactant and $\mathrm{pH}=11$ and by increasing the surfactant removal efficiency decreased. In all cases, removal efficiency for water (buffer solution) and acidic phases, are low. By increasing initial contamination, rate of removal efficiency increase, is reduced by increasing $\mathrm{pH}$ values, in fact in lower amounts of contamination, role of $\mathrm{pH}$ values in increasing efficiency is more significant. In all cases, by increasing surfactant amount, permeability reduces and in $\mathrm{pH}=11$ and surfactant percent of 0.1 , the highest permeability achieved. By increasing initial contamination, rate of increasing permeability is reduced by increasing $\mathrm{pH}$ values. In lower contamination amount, role of $\mathrm{pH}$ values on increasing permeability is more significant. Simultaneous assessment of remediation process and permeability for soil of $10000 \mathrm{ppm}$ contaminations, demonstrates that performing tests in the case of $\mathrm{pH}$ values of 9 and 11 and surfactant amount of 0.2 and $0.3 \%$ is a proper condition for soil remediation since efficiency increases in a ascending way and permeability does not reduced. Simultaneous assessment of remediation process and permeability for soil of $20000 \mathrm{ppm}$ contaminations, demonstrates that performing tests in the case of $\mathrm{pH}$ values of 7,9 and 11 and surfactant amount of $0.1 \%$ is a proper condition for soil remediation since efficiency increases in a ascending way and permeability does not reduce.

\section{REFERENCES}

Abdul, A.S., T.L. Gibson and D.N. Rai, 1990. Selection of surfactants for the removal of petroleum products from shallow sandy aquifers. Ground Water, 28: 920-926. DOI: 10.1111/j.1745-6584.1990.tb01728.x

Anderson, R., R. Elizabeth and V.R. Frank, 1999. Practice size separation via soil washing to obtain volume reduction. J. Hazardous Materials., 66: 89-98.

Anderson, W.C., 1995. Soil Washing/Soil Flushing.1st Edn., Springer-Verlag., Berlin, ISBN-10: 3540590625, pp: 174.
Chang, W., M. Dyen, L. Spagnuolo, P. Simon and L. Whyte et al., 2010. Biodegradation of semi-and nonvolatile petroleum hydrocarbons in aged, contaminated soils from a sub-Arctic site: Laboratory pilot-scale experiments at site temperatures. Chemosphere, 80: 319-326. PMID: 20471057

Coulon, F., E. Pelletier, L. Gourhant, D. Delille, 2005. Effects of nutrient and temperature on degradation of petroleum hydrocarbons in contaminated subAntarctic soil. Chemosphere, 58: 1439-1448. PMID: 15686763

Darban, A.K., H. Ganjdoust and M.A. Habibi, 2011. Evaluation of effective parameters and prediction of the natural bioremediation and transport of oil from Tehran refinery into groundwater. Proceedings of the International HSE Conference, (HSEC' 11), Tehran, Iran

Feng, D., L. Lorenzen, C. Aldrich, P.W. Mare, 2001. Ex situ diesel contaminated soil washing with mechanical methods, Miner. Eng., 14: 1093-1100.

Khalladi, R., O. Benhabiles, F. Bentahara, N. MoulaiMostefa, 2009. Surfactant remediation of diesel fuel polluted soil. J. Hazardous Mater., 164: 1179-1184. PMID: 18977072

Lee, D.H., H.W. Chang and R.D. Cody, 2004. Synergism effect of mixed surfactant solutions in remediation of soil contaminated with PCE. Geosci. J., 8: 319-323. DOI: 10.1007/BF02910251

Mulligan, C.N. and F. Eftekhari, 2003. Remediation with surfactant foam of PCP-contaminated soil. Eng. Geol., 70: 269-279. DOI: 10.1016/S00137952(03)00095-4

Shen, Y.H., 2000. Sorption of non-ionic surfactants to soil: The role of soil mineral composition. Chemosphere, 41: 711-716. PMID: 10834372

Taylor, T.P., K.D. Pennell, L.M. Abriola, J.H. Dan, 2001. Surfactant enhanced recovery of tetrachloroethylene from a porous medium containing low permeability lenses: 1. Experimental studies. J. Contam. Hydrol., 48: 325-350. DOI: 10.1016/S0169-7722(00)00185-6

Urum, K., P. Turgay and M. Copur, 2004. Surfactants treatment of crude oil contaminated soils. J. Colloid Interface Sci., 276: 456-464. DOI: 10.1016/j.jcis.2004.03.057 